
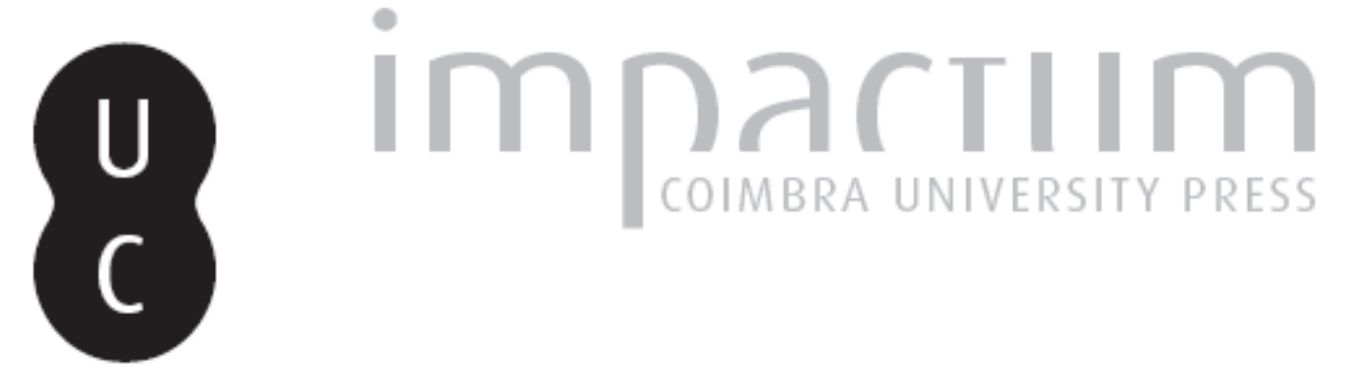

\title{
O terramoto de 1755 analisado 250 anos depois em colóquio multidisciplinar
}

\section{Autor(es): Rebelo, Fernando}

Publicado por: Associação Portuguesa de Riscos, Prevenção e Segurança

URL persistente:

URI:http://hdl.handle.net/10316.2/36205

DOI:

DOI:http://dx.doi.org/10.14195/1647-7723_15_10

Accessed : $\quad$ 26-Apr-2023 15:06:07

A navegação consulta e descarregamento dos títulos inseridos nas Bibliotecas Digitais UC Digitalis, UC Pombalina e UC Impactum, pressupõem a aceitação plena e sem reservas dos Termos e Condições de Uso destas Bibliotecas Digitais, disponíveis em https://digitalis.uc.pt/pt-pt/termos.

Conforme exposto nos referidos Termos e Condições de Uso, o descarregamento de títulos de acesso restrito requer uma licença válida de autorização devendo o utilizador aceder ao(s) documento(s) a partir de um endereço de IP da instituição detentora da supramencionada licença.

Ao utilizador é apenas permitido o descarregamento para uso pessoal, pelo que o emprego do(s) título(s) descarregado(s) para outro fim, designadamente comercial, carece de autorização do respetivo autor ou editor da obra.

Na medida em que todas as obras da UC Digitalis se encontram protegidas pelo Código do Direito de Autor e Direitos Conexos e demais legislação aplicável, toda a cópia, parcial ou total, deste documento, nos casos em que é legalmente admitida, deverá conter ou fazer-se acompanhar por este aviso.

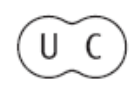




\section{territorium}

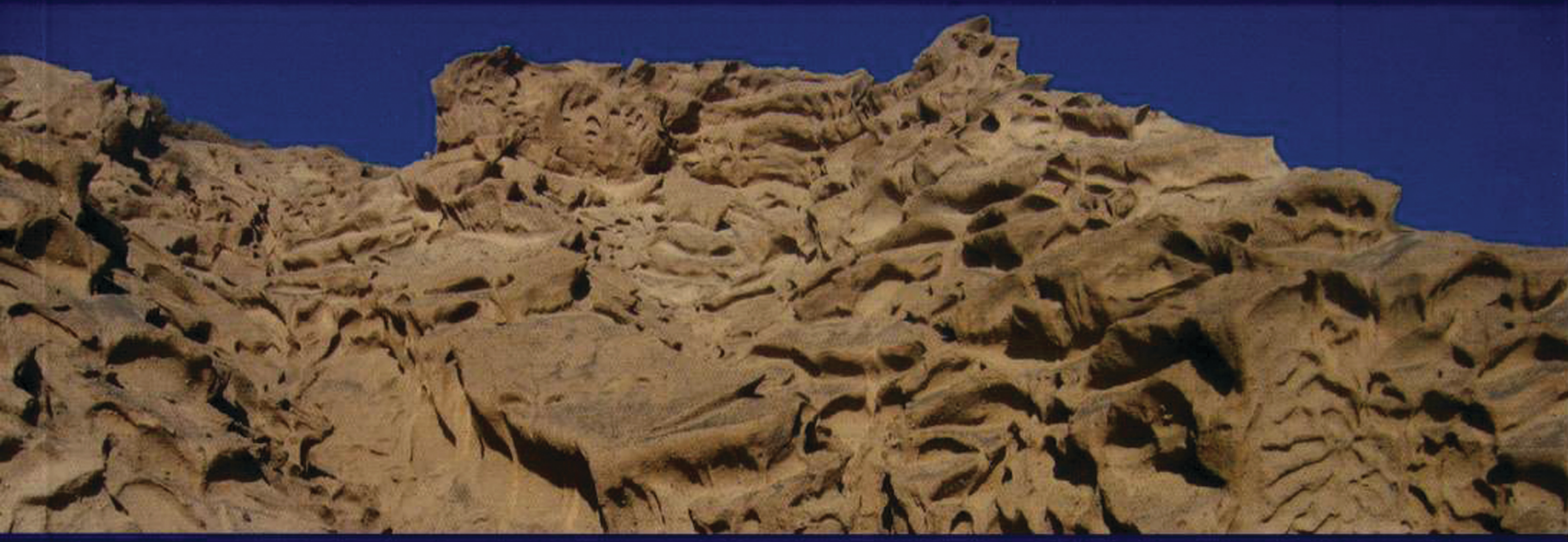

15

Revista da Associação Portuguesa de Riscos, Prevenção e Segurança 2008 


\section{O terramoto de 1755 analisado 250 anos depois em colóquio multidisciplinar}

Fernando Rebelo

Im finais de 2007, foram publicados em livro os trabalhos apresentados a um colóquio real izado dois anos antes pela Universidade Nova de Lisboa sobre o terramoto de 1755. Editado pelas Edições Colibri e pelo Instituto de História Contemporânea da Faculdade de Ciências Sociais e Humanas da Universidade Nova de Lisboa, intitula-se História e Ciência da Catástrofe e tem como subtítulo 250 Aniversário do terramoto de 1755. Além da introdução, assinada pelos coordenadores científicos, Maria Fernanda Rowo, Ana Isabel Buescu e Pedro CArum, este livro, de 207 páginas, publica 10 artigas da autoria de especialistas em áreas tão diversas como a História, a História da Arte, a Geologia, a Psicologia Social, a Arquitectura ou o Unbanismo.

O enquadramento do terramoto na História da Europa é, desde logo, estabelecido por Grégory Qtentr, no artigo intituladb "Le tremblement de terre de Lisbonne, un événement majeur de 1'Histoire Européenne" (p. 13-37) . O terramoto aparece relativizado no contexto das grandes catástrofes da época. 35 anos antes (1720) haviam falecido 100000 pessoas na Provence (França) em virtude da peste. Poucos anos antes (1737) e alguns anos depois (1789) centenas de milhar de pessoas morreram em virtude de ciclones na Índia, apesar de tudo, bem menos do que os 10 milhões de mortos pela fome na mesma área do globo (Bengala) em 1770 (p. 14). Para quem pensa que só agora hámuitos mortos en catástrofes (ditas) naturais estes números devem criar alguns problemas... No entanto, o Autor fala apenas em 10000 mortos na "capital portuguesa", o que parece um valor subestimado - os 40000 aceites por E. ZFBRonskr (1997) , 30000 no terramoto e 10000 no tsunami, talvez estejammais perto da triste realidade. Tentandb relativizar o terramoto de Lisbooa, Quenet também se refere a grandes sismos sentidos na capital portuguesa ao lango das séculos XVI (três) , XVII (três) emesmo XVII (dois) . Sabre um deles, o de 1551, fala em 2000 mortos. Apesar do movimento de solidariedade com Portugal que afima ter-se verificadb na Errropa, não pode deixar de salientar que, entre o 1 de Novembro de 1755 e os fins de 1756, se verificaram 44 sismos, só em França, pelo que, neste mesmo período, das 92 comunicações sobre sismos apresentadas à Academia das Ciências de Paris, só 2 se referiama Portugal. QkNE salienta que o terramoto foi uma catástrofe muito mediatizada, em que se e as diversas intenpretações" (p. 39-53) éo título do artigo seguinte da autoria de Maria Luísa BracA. Com ele ficamos a conhecer textos escritos por sobreviventes, como, por exemplo, "Moreira de Mendonça, então guarda-mor da Torre do Tombo" (p. 41) eMiguel Tíbério PhDFacte (p. 43), que se nos afiguram de grande credibi 7 idade. No entanto, estes e outros textos não permitem concluir a favor de umnúmero consensual de mortos. 'Onúmero de vítimas não é fácil de determinar. Nas suas descrições, os autores contemporâneos do terramoto atribuem, para Lisboa, um múmero muito variável" (p. 46) . Nb entanto, esses textos permitemnão só visualizar o acontecimento em si, mas também perceber como se processou a gestão da crise.

André Bro foi o autor de "A notícia do terramoto no sistema de informação do antigo regime" (p. 55-66) , artigo em que se salientam as dificuldades na chegada de notícias a diversas cidades europeias. En Gendbra, por exemplo, Voltaire poderá ter sabido do terramoto só a 23 de Novembro, por carta. En Lisboo, a Gazeta de Li isboca, saída a 6 e depois a 13 de Novembro "nunca dedicou, na secção reservada às notícias da Corte, mais do que algumas escassas linhas aos efeitos da catástrofe"..."Na Gazeta de Lisboa o terramoto não é notícia: o periódico não nos oferece nenhuma da informação específica que os historiadores nomalmente procuram sobre o terramoto, e encontram noutras fantes como as cartas" (p. 63) .

Seguidamente, em "Réplicas empapel (informação e comentário)" (p. 67-82) , João Luís Li\$sła, dedica-se à apreciação de textos publicadas pasteriormente. "Os acontecimentos foram motivo imediato para o prol iferar de reacções, ecos, narrações e comentários que se sucederam por meses e anos" (p. 67). O autor mostra reproduçães de gravuras e junta versos, além de vários textos que circularam entre 1755 e 1756, salientando que "oficina da curiosidade é a designação escolhida para organizar a maior colecção de folhetos sobre o terramoto, em cinco volumes, datada de 1758 e guardada na Biblioteca Nacional, em Lisboo" (p. 82) .

Por sua vez, Maria Luísa Pedroso DE LiMA assina O artigo "Natureza e gestão do risco: interpretaçães do terramoto nos textos da época" (p. 83-102) . Iniciando o seu trabalho por dizer que "o terramoto de 1755 pôs a nu algumas clivagens na maneira de pensar a vida, a natureza e a organização social" (p. 83) , a autora fala em "terramotos e temor" e estabelece comparação com o que pôde estudar nos Açores quando do sismo de 1 de Janeiro de 1980 (p. 88) . 
Năo duvida que, em 1755, "a estratégia mais comm consistia emprocurar a protecção divina", mas aponta elementos importantes sobre "uma estratégia de controlo político sobre o sismo", da responsabilidade do Marquês de Pombal, e que corresponde ao que hoje consideraríamos uma notável gestão da crise, envolvenob soldados, vereadores muicipais, juízes e clérigos (p. 90) . Neste trabolho, não poderemos deixar de chamar a atenção das potenciais interessados para as referências bibliográficas que coupammais de duas páginas (p. 100-102) .

A reconstrução pós-terramoto é apresentada por Raquel Henriques da Sma em "Da destruição de Lisbooa ao arrasamento da Baixa: o terramoto urbanístico de Lisboa" (p. 103-111) . Ao contrário do que se poderia prever, a autora não se limita a falar da "Baixa Pombalina". Vai bemmais longe, como, por exemplo, a Campo de Ourique ou à Ajuda, mostrando que o terramoto "mexeu" com toda a cidade.

António Ribirp, ao escrever sobre "Génese das sismos: o sismo de 01/11/1755. Significado geodinâmico" (p.113-123), desce ao ceme das questões que se encontram na base deste e de outros grandes sismos verificados em Portugal. Depois de uma introdução teórica sabre sismos e tsunamis (p. 113-116) , disarte a localização exacta do epicentro, deixando muito claro que o tão falado "Banco de Goringe", onde "o cavalgamento é inactivo há cerca de 5 milhões de anos", não pode ser considerado como "fonte para o sismo de 1755" (p. 116). Argumenta, então, a favor do "Carreamento de Marquês de Pombal (margem SN-Ibérica)", dado que "perfis de reflexão sísmica" provam "a existência cerca de 100 km a SW do Cabo de São Vicente de um carreamento orientado NNESSW, que provoca o levantamento do fundo de mais de 1 km sobre os fundos oceânicos a hMW" (p. 116) . No entanto, "como o carreamento do Marquês de Pombal se estende apenas por $55 \mathrm{~km}$ seria insuficiente para gerar a nuptura responsável por um sismo da magnitude estimada para 1755, de 8,7", acrescenta fontes adicionais. Una delas parece-lhe ter sido essencial, "a solução da Falha inversa da Ferradura é a mais plausível porque a situação de quase continuidade e orientação sub-paralela como sistema de carreamento do Marquês de Pombal faci 7 ita a transferência da tensão geradbra de sismos entre os dois sistemas" (p. 117). Também neste trabalho há uma bibliografia de grande interesse, ocupando praticamente três páginas (p. 121-123) .

Ana Cristina Arúxo mais uma vez aparece ligada ao terramoto de 1755. Agora, como autora do artigo "Armadilhas da razão prática: desastre, risco e propaganda" (p. 125-153) . Primeiro é o desastre, isto é, a catástrofe, com toda a destruição que lhe ficou associada, não apenas em Lissboa, mas igualmente "no Algarve, especialmente no Barlavento, sul de Espanha e Marrocos". Depois é "a (des) construção da catástrofe", através do que se escreveu pela flrropa, fosse na Gazette de Cologne ou na "Gazeta de Utreque, fosse em cartas ou outros escritos, com descrições vividas de estrangeiros que, à data, se encontravam em Lisisoa. Por vezes, há referências a comparações con catástrofes ocorridas natros territórios enatros tempos, bem como a interpretações diversas provenientes de diversos países europeus. A Guerra dos Sete Anos (1756-1763) terá indubitavelmente influência no pós-terramoto e emmuito do que se di.sse e escreveu. Naúl tima parte do seu trabalho, Ana Araújo fala ca "História oficial da catástrofe". . Neste contexto refere As Memórias cás Principais Providências que se deram no Terramoto que padeceu a corte de Li.sboa no ano de 1755, publicadas em 1758 e que foram divulgadas en França através de artigos laudatórios para a monarquia portuguesa em 1759 e 1760 . Tomase, então, muito claro que o poder público transformou a tragédia de um dia num dia seguinte de grande bri 7ho - "O Diário das Sucessos de Lisbooa, reimpresso en 1766, circula por toda a Europa, com o objectivo de dar a conhecer a esclarecida govemação do futuro Marquês de Pombal e de mostrar que o terramoto de 1755 representava para os sábios e homens de acção o princípio de uma nova era, de progresso e de glória para Portugal" (p. 152) . O artigo de Ana Araújo é, ainda, enriquecido com numerosas notas infrapaginais, onde se podem encontrar as fontes ea bibliografiautilizadas.

"O terramoto político (1755-1759) . Portugal aflito e conturbado" (p. 155-185) , assinado por José Stirlu, começa por apresentar uma situação de "colapso da administração régia" para seguir para uma situação em que são nítidos "os rumos da centralização". Aqui, discute-se o caso do atentado a D. Jasé, como se disaute a expulsão das jesuítas. E, como escreve o Autor "é bem provável que, sobrecarregado com as desgraças do terramoto, D. José tenha encontrado na fimeza do ministro a inflexibilidade política que se ajustava aos acontecimentas e circunstâncias" (p. 181) . De notar que, também este artigo, é enriquecido por uma longa bibliografia (p. 182-185) .

Finalmente, "Dinâmicas espaço-funcionais do centro histórico" (p. 187-207), da autoria de Teresa Valssassina Hercr, parte do conceito de centro histórico e da sua dinâmica de transformação, passa pelos conceitos de renovação e reabilitação, dando o caso 
de Barcelona, para terminar falando dos centros históricas em Portugal. Năo se refere ao terramoto, embora se compreenda a razão de ser do trabalho.

História e ciência da Catástrofe. 250 Aniversário do terramoto de 1755 é um livro importante não só para as Ciências Cindínicas, também chamadas Ciências do Perigo ou, melhor ainda, Ciências do Risco, mas também para a Geologia, a Geografia e a História de Portugal. Georges-Yves KerkHN e Patrick Riniss foram pioneiros nestas Ciências, que virama sua designação proposta apenas en 1987. No seu livro, L Archipel au Danger, falaram do terramoto de Lisboa logo na introdução a que deram o título de "Lisbonne 1755. Tremblement de terre. Rousseau révolutionne le danger" (G-Y. KerkerN; P. RuBIs, 1991) . Desde então, a maior parte dos livros publicados sobre riscos não mais deixaram de dedicar algumas linhas ou até várias páginas à catástrofe de Lisboa, "mas aqui explica-se bem porquê - depois de uma 'idade do sangue' em que o homem acalmava a fúria dos deuses com sacrifícios humanos, passau-se, como cristianismo, à 'idade das lágrimas', en que 'as grandes medos.são geradores de preces e procissões', para, com a discussão que, a propósito do terramoto de Lisboa, se estabeleceu entre Voltaire e Rousseau sobre o lugar do homem e de Deus nas catástrofes', aparecer a revolução do perigo" (G. Y. Kerren e P. Ruiss, citados por F. Rwro, 2005, p. 67) . Pessoalmente, chamar-lheia a revolução do risco, mas, em 1991, as Ciências Cindínicas estavamno princípio e os conceitos ainda não se apresentavam bem definidos. Agora, que já se sabe, claramente, oqueérisco, perigo e crise ( $F$. Rmo, 2001, 2003) , havendo consciência do risco sísmico em Portugal, há consciência da probabi lidade da sua manifestação. Poderá acontecer apenas um pequeno sismo, uma situação de perigo. Mas poderá ocorrer um terramoto, com destruições. Será uma crise de que o homem já só poderá tentar gerir os efeitos. Se essa crise voltar a ser mortífera, teremos de novo uma catástrofe. Esperamos, tocavia, quenão seja tão grave, atendendo à diminuição das vulnerabilidades que se iniciou com a reconstrução de Lisbooa após 1755 e que tem continuado até aos nossos dias com o aperfeiçoamento das técnicas e da legislação relacionadas coma construção anti-sísmica. Estudas realizados em 2005 pelo Laboratório Nacional de Engenharia Civil e dados a conhecer pelo Semanário Expresso (Cademo Actual, Lisboa, 22 de Outubro de 2005) mostram que, para um sismo da mesma intensidade do então verificado em Lisboa, hoje, as perdas seriam, proporcionalmente, muito menores 1\% da população contra os 10\% de 1755. Mas não deixaria de ser una catástrofe.

\section{Referências bibliográficas:}

KERNHN, Georges-Yves; RUBISE, Patrick (1991) L Archipel du Danger. Introouction aux Cindiniques. Paris, Económica, 444 p.

Rewro, Fernando (2001) - Riscos Naturais e Acção Antróoica. Coimbra, Imprensa da Universidade, 274 p. (2 edição, revista e aumentada: 2003, 286 p.)

Remo, Femando (2005) - Uma Experiência Eurropeia em Riscos Naturais. Coimbra, MinervaCoimbra, 123 p.+23 fotografias a preto eloranco, extra-texto.

Rouro, Maria Fernanda; Buescu, Ana Isabel; CARDIM, Pedro (coordenadores científicas) (2008) - História e Ciência da Catástrofe. 250 Aniversário do terramoto de 1755. Lisbooa, Ebiç̧oes Colibri e Instituto de História Contemporânea da Faculdade de Ciências Sociais e Humanas da Universidade de Lisboa, $207 \mathrm{p}$.

ZHFonsI, Emest (1997) - Perils of a Restless Planet. Scientific Perspectives on Natural Disasters. Cambridge University Press, 306 p. 